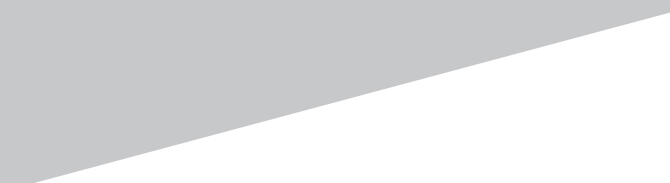

\title{
EXPERIÊNCIAS DISCRIMINATÓRIAS: NARRATIVAS DE UNIVERSITÁRIOS DO SUL do BRASIL
}

\author{
Discriminatory experiences: narratives of undergraduate students
} from Southern Brazil

\author{
Alexandre Baumgarten ${ }^{a}$ \\ Giovane De Carli ${ }^{b}$ \\ Pamela Kargwanskic \\ João Luiz Bastos ${ }^{\mathrm{d}}$ \\ Roger Keller Celeste ${ }^{\mathrm{e}}$ \\ Ramona Fernanda Ceriotti Toassi ${ }^{f}$
}

\section{RESUMO}

Introdução: A discriminação é um fenômeno injusto, evitável e condenável que pode afetar negativamente a vida e a saúde dos indivíduos. Objetivo: Compreender experiências discriminatórias vivenciadas e presenciadas ao longo da vida de estudantes universitários de uma capital no Sul do Brasil. Metodologia: Estudo exploratório de abordagem qualitativa realizado por meio de entrevistas individuais semiestruturadas, gravadas e transcritas, com estudantes de graduação vinculados a cursos com distintas relações candidato/vaga, com diversidade quanto ao sexo, idade, cor da pele/raça e etapa da formação (amostra final = 15). O material textual foi interpretado pela técnica da análise temática de conteúdo de Bardin. Resultados: Experiências discriminatórias passadas ou atuais, vivenciadas e/ou presenciadas estiveram presentes nos depoimentos de 14 dos 15 estudantes, os quais reconheceram a discriminação como um comportamento que expressa diferenças de tratamento em relação ao outro por determinadas características, implicando ofensa, prejuízo e exclusão social das vítimas. Nas experiências discriminatórias, as que envolveram pessoas próximas dos estudantes, de seu núcleo familiar, foram as que mais os afetaram negativamente. Foram relatados múltiplos motivos associados à discriminação, em meio a situações nas quais os estudantes se identificaram tanto como vítimas quanto perpetradores de tratamentos injustos. O sentimento de solidariedade às vítimas da discriminação também foi evidenciado pelo grupo. Conclusão: Múltiplas experiências de discriminação foram relatadas, evidenciando a pluralidade e a complexidade o fenômeno. Este estudo tem potencial para contribuir com a compreensão da discriminação, auxiliando no desenvolvimento/validação de medidas quantitativas de fenômenos de ordem social.

Palavras-chave: Discriminação social. Educação superior. Estudantes. Relações interpessoais. Pesquisa qualitativa.

\footnotetext{
a Mestre e Doutorando em Epidemiologia, Programa de Pós-Graduação em Epidemiologia, Universidade Federal do Rio Grande do Sul, Porto Alegre, RS, Brasil.

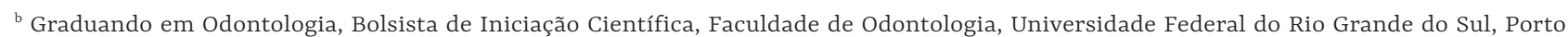
Alegre, RS, Brasil.

c Graduanda em Odontologia, Faculdade de Odontologia, Universidade Federal do Rio Grande do Sul, Porto Alegre, RS, Brasil.

d Professor do Departamento de Saúde Pública, Universidade Federal de Santa Catarina, Florianópolis, SC, Brasil.

e Professor do Departamento de Odontologia Preventiva e Social, Universidade Federal do Rio Grande do Sul, Porto Alegre, RS, Brasil. ${ }^{\mathrm{f}}$ Professora do Departamento de Odontologia Preventiva e Social, Universidade Federal do Rio Grande do Sul, Porto Alegre, RS, Brasil. Autora de correspondência: Ramona Fernanda Ceriotti Toassi - E-mail: ramona.fernanda@ufrgs.br 


\section{ABSTRACT}

Introduction: Discrimination is an unfair, avoidable and unnecessary phenomenon that can negatively affect the life and health of individuals. Objective: To understand discriminatory situations experienced or observed by undergraduate students over their life course in a state capital in the South of Brazil. Methodology: Exploratory research of qualitative approach. The data were collected based on semi-structured interviews undergraduate students; then recorded and transcribed. Students were selected to assure diversity, using the number of candidate per vacancy, sex, age, skin color/race and stages in their course as indicators (final sample $=15$ ). The textual material was interpreted using thematic content analysis of Bardin. Result: Discriminatory experiences experienced and/or witnessed were present in interviews of 14 students, who recognize discrimination as a different treatment to another person because of certain characteristics, implying any kind of offense, injury and social exclusion to the victims. Discriminatory experiences towards interviewees' friends or relatives affected them more than towards themselves. Multiple reasons associated with discrimination were reported, amid situations in which the students identified themselves as both victims and perpetrators of unfair treatment. The feeling of solidarity with the victims of discrimination was evidenced by the group. Conclusion: The university was identified as a space where discrimination occurs, especially for sexual reasons and to pertaining to a specific course, as a night course. This qualitative study can contribute to the understanding of discrimination and therefore help developing valid quantitative measures to be used in larger surveys.

Keywords: Social discrimination. Higher education. Students. Interpersonal relations. Qualitative research.

\section{INTRODUÇÃO}

A discriminação corresponde um conjunto de comportamentos observáveis, que se manifestam pelo tratamento diferencial e injusto a pessoas ou grupos em razão das suas origens, suas pertenças, aparências ou das suas opiniões, reais ou supostas ${ }^{1,2}$. Trata-se, portanto, de uma experiência que necessariamente envolve interações sociais ${ }^{3}$. O interesse científico pela temática tem se expressado pelo crescente número de publicações em diferentes áreas do conhecimento científico, incluindo a de saúde pública ${ }^{4}$. Estudos em adolescentes e adultos demonstram prevalências de discriminação que variam de $21 \%$ a $75 \%{ }^{5,6,7}$, podendo o tratamento discriminatório ocorrer em variados espaços, como no local de trabalho ${ }^{8}$, espaços públicos ${ }^{8,9}$, escola ${ }^{10}$ e universidade ${ }^{11}$. O ambiente familiar também se constitui lócus de manifestação dos eventos discriminatórios ${ }^{12}$.

Experiências discriminatórias têm sido associadas a efeitos deletérios para a saúde da população em geral $^{13}$, incluindo sintomas depressivos ${ }^{14}$, ansiedade e diminuição do bem-estar ${ }^{15}$, aumento da frequência cardíaca ${ }^{16}$, produção crônica de hormônios relacionados ao estres$\mathrm{se}^{17}$ e sofrimento psíquico ${ }^{18}$. Tais consequências podem levar as vítimas da discriminação a adotar comportamentos deletérios, como o aumento no consumo de álcool ${ }^{19}$, ou reduzir seu engajamento em comportamentos benéficos à saúde ${ }^{15}$. Nos espaços acadêmicos, a percepção da discriminação pode influenciar negativamente a motivação dos estudantes, afetar seu desempenho escolar, sua probabilidade de evasão, autoestima, satisfação com a vida, níveis de ansiedade e comportamentos agressivos ${ }^{20}$.

O foco dos estudos sobre discriminação tem se ampliado ao longo do tempo, não se restringindo às experiências exclusivamente raciais, mas também, abrangendo outras formas de tratamento injusto, como a discriminação por gênero, classe e orientação sexual ${ }^{2,21,22}$. Entretanto, ainda há poucos trabalhos investigando experiências discriminatórias em meio a diferentes estratos populacionais, sob uma perspectiva ampliada e não restrita a algum tipo particular de discriminação $0^{11,23}$. Em particular, há necessidade de se conhecer possíveis diferenças regionais na forma como a discriminação se expressa, os locais de manifestação, 
eventuais sentimentos que emergem a partir dela e impactos para a saúde, além do contexto sociocultural no qual a mesma se manifesta.

Partindo do entendimento que a discriminação se refere a um fenômeno injusto, evitável e condenável, este estudo propôs-se a compreender experiências discriminatórias vivenciadas e presenciadas ao longo da vida de estudantes universitários de uma capital no sul do Brasil.

\section{Metodolocia}

Trata-se de uma pesquisa exploratória com abordagem qualitativa, cujo campo de investigação foi uma universidade pública do Sul do Brasil. Tal instituição de ensino superior público foi selecionada por contemplar populações com diferentes origens sociais, de alta e baixa renda, egressos de escola pública e privada e por apresentar sistema de ingresso orientado pela política de cotas sociais e raciais ${ }^{24}$.

A produção de informações ocorreu por meio da realização de entrevistas individuais, guiadas por roteiro semiestruturado ${ }^{25,26}$, realizadas por três pesquisadores com experiência em pesquisa qualitativa. O roteiro pré-testado contemplava três tópicos principais (Tópico 1: Entendimento do conceito de discriminação; Tópico 2: Situações e experiências consideradas discriminatórias; e Tópico 3: Sentimentos associados à discriminação). Estes tópicos foram construídos a partir do roteiro do grupo focal e das categorias de análise do estudo de Bastos et al. ${ }^{23}$. Todas as transcrições foram devolvidas aos entrevistados para que pudessem lê-las e que tivessem a oportunidade de, verificar se estavam de acordo com as ideias apresentadas e, se julgassem necessário, se havia necessidade de complementar ou modificar seus depoimentos.

A amostra foi intencional, buscando relatos das experiências de discriminação dos universitários a partir de uma perspectiva abrangente e não restrita a um tipo particular de discriminação. Foram convidados a participar das entrevistas estudantes de cursos de graduação com distintas relações candidato/vaga (avaliado pela densidade de ingresso no momento do vestibular), de ambos os sexos, com idades variadas e que estivessem em diferentes etapas da formação. No que se referiu à cor/raça, essa também foi uma característica considerada para a seleção dos participantes do estudo, tomando-se o cuidado de ter a presença de estudantes brancos, pardos e negros na amostra.

A estratégia adotada na seleção dos participantes seguiu os princípios adotados na técnica da bola de neve, ou seja, após a realização de uma primeira entrevista com um estudante indicado por sua vivência pessoal, os pesquisadores selecionaram um segundo entrevistado, o qual foi recomendado pelo primeiro entrevistado. Esse processo foi repetido até que os pesquisadores constataram a saturação amostral, não se encontrando em novas entrevistas informações que pudessem trazer significados adicionais aos resultados do estudo. O convite para os estudantes participarem da pesquisa aconteceu por contato pessoal entre os pesquisadores e entrevistados. Todos os estudantes convidados aceitaram participar da pesquisa.

As entrevistas foram realizadas em espaços da própria universidade, a partir da disponibilidade desses estudantes, como salas de aulas, salas de estudo reservadas, ou, ainda, em espaços públicos da universidade, sempre mantendo a privacidade do entrevistado. As entrevistas realizadas eram gravadas, transcritas na íntegra e, após, examinadas pela equipe de pesquisa, buscando aprimorar a condução das questões norteadoras pelos pesquisadores entrevistas.

Ao final, 15 universitários foram entrevistados em um período de 10 meses. A duração das entrevistas variou de 15 a 45 minutos, totalizando quatro horas de gravação. Não está incluído nesse tempo, a explicação dos objetivos da pesquisa e leitura do Termo de Consentimento Livre e Esclarecido. 
A análise dos resultados foi descritiva, pela técnica da análise temática de conteúdo de Bardin ${ }^{27}$, sendo apresentada em categorias emergentes, ou seja, unidades de significação das narrativas de estudantes universitários em relação às experiências discriminatórias vivenciadas e/ou presenciadas no curso das interações humanas com o mundo ${ }^{28}$. A pesquisa foi aprovada pelo Comitê de Ética em Pesquisa da universidade (CAAE n. ${ }^{\circ}$ 15322813.6.0000.5347, Parecer n. ${ }^{\circ}$ 303.041).

\section{Resultados E discussão}

Participaram das entrevistas 15 estudantes universitários, matriculados em nove diferentes cursos de graduação, de ambos os sexos e com idade entre 20 e 42 anos (Tabela 1).

Tabela 1: Caracterização da amostra.

\begin{tabular}{|c|c|}
\hline Variáveis & $\mathbf{n}$ \\
\hline \multicolumn{2}{|l|}{ SEXO } \\
\hline Feminino & 9 \\
\hline Masculino & 6 \\
\hline \multicolumn{2}{|l|}{ IDADE } \\
\hline 20-22 anos & 7 \\
\hline 23-25 anos & 5 \\
\hline 26-27 anos & 2 \\
\hline 42 anos & 1 \\
\hline \multicolumn{2}{|l|}{ COR DA PELE/RAÇA (AUTODECLARADA) } \\
\hline Branca & 13 \\
\hline Parda & 1 \\
\hline Preta & 1 \\
\hline \multicolumn{2}{|l|}{ CURSO DE GRADUAÇÃO } \\
\hline Odontologia & 5 \\
\hline Química Industrial & 1 \\
\hline Educação Física & 1 \\
\hline Medicina & 2 \\
\hline Administração & 1 \\
\hline Jornalismo & 1 \\
\hline Arquitetura & 2 \\
\hline Psicologia & 1 \\
\hline Estatística & 1 \\
\hline \multicolumn{2}{|l|}{ TIPO DE EXPERIÊNCIA DISCRIMINATÓRIA } \\
\hline Vivenciada (experiência pessoal) & 7 \\
\hline Presenciada (com outras pessoas) & 1 \\
\hline Vivenciada e presenciada & 6 \\
\hline Não vivenciou nem presenciou & 1 \\
\hline
\end{tabular}


A interpretação do material textual das entrevistas está apresentada em duas categorias principais: ‘Discriminação: do que tratam as experiências dos estudantes?' e 'Compreendendo a experiência discriminatória: motivos, local, relato e sentimentos”.

\section{Discriminação: do que tratam as experiências dos estudantes?}

Para que a experiência discriminatória possa ser adequadamente interpretada, é preciso, em um primeiro momento, entender sobre o que os estudantes estão falando quando se referem a essa questão. Academicamente, a discriminação é entendida como um processo pelo qual um membro/membros de um grupo socialmente definido é, ou são tratados de forma diferente, especialmente de modo injusto ${ }^{2}$. Nesse sentido, a discriminação inclui não somente ações que trazem prejuízo ou desvantagem para outro grupo, como também aquelas que favorecem injustamente o grupo do próprio perpetrador que cometeu a discriminação ${ }^{29}$.

No presente estudo, os estudantes reconheceram o fenômeno da discriminação associado a um comportamento que expressa diferenças em relação ao outro por determinadas características (físicas, comportamentais ou socialmente atribuídas), considerando-a negativa, sendo capaz de trazer ofensa, prejuízo e exclusão social às suas vítimas.

Discriminação é o ato, está discriminando [...]. Discriminar é negativo, é porque tu está ofendendo alguém. (Estudante 1, sexo feminino, 20 anos)

[...] eu entendo quando é discriminação, tu está aplicando uma ofensa a alguém. Na discriminação, tu está agindo prejudicialmente a alguém [...]. (Estudante 8, sexo masculino, 20 anos)

Discriminação é quando tu exclui a pessoa de alguma forma, por um aspecto físico, um aspecto psicológico dela, social. (Estudante 6, sexo feminino, 20 anos)

Caracterizada como uma manifestação do preconceito ${ }^{30}$, a discriminação é um tratamento desfavorável, negativo ${ }^{31}$, ligado ao plano das ações e que possibilita práticas de violência, uma vez que fomenta relações sociais hostis ${ }^{32}$. São essas experiências discriminatórias, essencialmente negativas, que emergiram das entrevistas com os estudantes e que serão abaixo analisadas.

\section{Compreendendo a experiência discriminatória: motivos, local, situação e sentimentos}

Experiências discriminatórias são fenômenos complexos e difíceis de serem mensurados, mas que são recorrentes na vida das pessoas, sendo motivadas por diferentes características ${ }^{23}$. Entre os universitários entrevistados, observou-se que experiências discriminatórias vivenciadas e/ou presenciadas fizeram parte da vida de 14 dos 15 estudantes. Destas experiências, 13 foram narrativas que refletem a condição de vítimas da discriminação e, por sua vez, uma que se refere à perpetração da discriminação contra outros indivíduos.

Os Quadros 1 e 2 sintetizam as experiências discriminatórias, vivenciadas e presenciadas, respectivamente, e os sentimentos que emergiram no grupo universitário estudado. Esse sentimento trata-se da percepção do estudante entrevistado sobre o que vivenciou ou sobre o que sentiu ao presenciar uma situação discriminatória. 
Quadro 1: Motivo, local, relato da experiência e sentimentos dos estudantes em relação à experiência discriminatória vivenciada.

\begin{tabular}{|c|c|c|c|}
\hline $\begin{array}{l}\text { MOTIVO DA } \\
\text { DISCRIMINAÇÃO }\end{array}$ & LOCAL & $\begin{array}{l}\text { EXPERIÊNCIA DISCRIMINATÓRIA } \\
\text { VIVENCIADA }\end{array}$ & SENTIMENTOS \\
\hline $\begin{array}{l}\text { Aparência física (usar ócu- } \\
\text { los) associada à compor- } \\
\text { tamento mais quieto }\end{array}$ & Escola & $\begin{array}{l}\text { Me chamavam de 'retardada', 'mongo- } \\
\text { lona', essas coisas. [...] muito poucos } \\
\text { colegas usavam óculos, né? A maioria } \\
\text { era sem, logo eu era a diferente, eu era } \\
\text { a anormal, então, muitas vezes eles } \\
\text { me excluíam, assim, por causa disso. E } \\
\text { também por eu ter um comportamento } \\
\text { mais quieto, eu não interagia com toda } \\
\text { turma, eu interagia com alguns poucos. } \\
\text { E a minha própria vergonha, porque eu } \\
\text { sabia que era feio, sabia que era ridículo } \\
\text { usar óculos e acabava meio que ficando } \\
\text { inibida, eu ficava inibida e não criava } \\
\text { maiores amizades. (Entrevista 3) }\end{array}$ & $\begin{array}{l}\text { Baixa autoestima, ini- } \\
\text { bição para amizades, } \\
\text { tristeza e humilhação, } \\
\text { vergonha, muito } \\
\text { prejuízo na vida social } \\
\text { e emocional }\end{array}$ \\
\hline $\begin{array}{l}\text { Aparência física } \\
\text { (usaróculos, ter orelha } \\
\text { grande) }\end{array}$ & Escola & $\begin{array}{l}\text { [...] pelos óculos, mais quando eu era } \\
\text { criança. [...] acho que foi quando eu } \\
\text { comecei a usar óculos, eu estava sei lá, } \\
\text { acho que na quarta série por aí, os me- } \\
\text { ninos, aquela coisa de: 'ah, quatro olhos, } \\
\text { quatro olhos', aquela coisa, normal... } \\
\text { tanto é que por isso que eu odeio, tipo } \\
\text { sempre odiava usar óculos. (Entrevista 6) } \\
\text { Eu tinha orelha grande, então me cha- } \\
\text { mavam de 'dumbinho' (Entrevista 15) }\end{array}$ & Tristeza e incômodo \\
\hline Cor da pele (racial) & Escola & $\begin{array}{l}\text { Pra mim foi uma coisa assim marcante, } \\
\text { porque eu lembro da transição que eu } \\
\text { tive de escola, eu saí de uma escola pú- } \\
\text { blica onde todo mundo era uma mistura, } \\
\text { tu tem de todas as cores na verdade, eu } \\
\text { entro numa escola particular, onde são } \\
\text { a maioria pessoas brancas, né, negros } \\
\text { são poucos e eu me senti particular- } \\
\text { mente bastante excluída assim, logo } \\
\text { no primeiro ano, é uma fase nova e eu } \\
\text { fui sim excluída em parte, e eu atribuo } \\
\text { isso a minha cor. Eu ouvi neguinha, ouvi } \\
\text { comentários, ouvi coisas que me fizeram } \\
\text { acreditar que era isso a causa. [...] os ape- } \\
\text { lidos que deram, sabe esses risinhos, e } \\
\text { pequenas coisas, nomes que atribuem a } \\
\text { quem tem cor, enfim, é o que me fizeram } \\
\text { a acreditar que foi uma situação dessas. } \\
\text { (Entrevista 5) }\end{array}$ & $\begin{array}{l}\text { Frustração, muita } \\
\text { tristeza, sentimento } \\
\text { de reclusão, de impo- } \\
\text { tência para mudara } \\
\text { percepção das pessoas }\end{array}$ \\
\hline
\end{tabular}


Quadro 1 (cont.)

\begin{tabular}{|c|c|c|c|}
\hline $\begin{array}{l}\text { MOTIVO DA } \\
\text { DISCRIMINAÇÃO }\end{array}$ & LOCAL & $\begin{array}{l}\text { EXPERIÊNCIA DISCRIMINATÓRIA } \\
\text { VIVENCIADA }\end{array}$ & SENTIMENTOS \\
\hline $\begin{array}{l}\text { Cor da pele (racial) } \\
\text { associada à condição } \\
\text { econômica }\end{array}$ & Escola & $\begin{array}{l}\text { O pessoal ficava me chamando de ale- } \\
\text { mão e eu era o único tão loiro assim na } \\
\text { turma sabe, e daí eles ficavam pegando } \\
\text { no meu pé por isso. [...] acho que o que } \\
\text { mais pegava era por isso, eles ficavam } \\
\text { me tirando pra alemão, 'tu não tá no } \\
\text { meu grupo', por não ser tão chegado. Só } \\
\text { que na minha turma praticamente tinha } \\
\text { eu, tinha um outro colega loiro só que } \\
\text { ele era bem riquinho sabe, e ele não era } \\
\text { preconceituoso, ele era legal, só que o } \\
\text { pessoal pegava no meu pé e no pé dele } \\
\text { não pegava, e no caso ele era bem cheio } \\
\text { da grana, que nem eu disse, talvez então } \\
\text { tenha a ver mais por questões finan- } \\
\text { ceiras, dessa forma eu percebi que era } \\
\text { desigual. (Entrevista 8) }\end{array}$ & $\begin{array}{l}\text { Tristeza, insegurança e } \\
\text { vergonha }\end{array}$ \\
\hline Por ser estudioso & Escola & $\begin{array}{l}\text { Ser chamado de 'cdf'/estudioso. } \\
\text { (Entrevista 9) }\end{array}$ & $\begin{array}{l}\text { Vermelhidão, pernas } \\
\text { trêmulas e raiva }\end{array}$ \\
\hline Sexual & Universidade & $\begin{array}{l}\text { Relacionado a tratamento diferenciado } \\
\text { como se fosse algo desmoralizante pelo } \\
\text { fato de eu ser homossexual. Hoje na } \\
\text { Faculdade, o fato de no trote ter todo um } \\
\text { "jogo" em que na verdade acabavam te } \\
\text { pressionando mais psicologicamente, te } \\
\text { colocando em um constrangimento. 'Ah, } \\
\text { tu é ou não é gay, tu gosta de homem ou } \\
\text { não?' (Entrevista 12) }\end{array}$ & $\begin{array}{l}\text { Indiferença e depois } \\
\text { sentimento depres- } \\
\text { sivo, certa inibição, } \\
\text { constrangimento, } \\
\text { aceleração cardíaca, } \\
\text { gagueira, rosto rubo- } \\
\text { rizado }\end{array}$ \\
\hline $\begin{array}{l}\text { Por ser estudante de curso } \\
\text { noturno }\end{array}$ & Universidade & $\begin{array}{l}\text { Eu queria ser monitor [...] na faculdade, } \\
\text { e daí eu senti que por eu ser do noturno, } \\
\text { eu não sou tão qualificado quanto são os } \\
\text { do diurno, enquanto os do diurno têm } \\
\text { a opção de fazer o que eles quiserem, } \\
\text { serem monitores do que eles quiserem... } \\
\text { (Entrevista 2) }\end{array}$ & $\begin{array}{l}\text { Ansiedade, gastrite e } \\
\text { refluxo }\end{array}$ \\
\hline
\end{tabular}


Quadro 2: Motivo, local, relato da experiência e sentimentos dos estudantes em relação à experiência discriminatória presenciada.

\begin{tabular}{|c|c|c|c|}
\hline $\begin{array}{l}\text { MOTIVO DA } \\
\text { DISCRIMINAÇÃO }\end{array}$ & LOCAL & $\begin{array}{l}\text { EXPERIÊNCIA DISCRIMINATÓRIA } \\
\text { PRESENCIADA }\end{array}$ & SENTIMENTOS \\
\hline Cor da pele (racial) & Rua & $\begin{array}{l}\text { Tinha um amigo na minha infância que } \\
\text { ele era negro, ele era filho de uma em- } \\
\text { pregada doméstica que tinha no prédio } \\
\text { do lado, e a gente vivia brincando junto } \\
\text { na rua, mas quando a gente se desenten- } \\
\text { dia eu acabava excluindo ele do grupo, } \\
\text { chamando ele de negro; 'saí daqui, por- } \\
\text { que tu é preto, porque tu é burro', essas } \\
\text { coisas assim... (Entrevista 3) }\end{array}$ & $\begin{array}{l}\text { Perpetrador: muito } \\
\text { 'poderosa'. Atualmente } \\
\text { sente arrependimento. } \\
\text { Vítima: humilhação }\end{array}$ \\
\hline Corda pele (racial) & Trânsito & $\begin{array}{l}\text { [...] meu pai já foi xingado diversas vezes } \\
\text { no trânsito, se ele faz alguma besteira } \\
\text { não é como uma pessoa que é chamada } \\
\text { a atenção, uma buzinada, tipo, chamam } \\
\text { de 'negão' mesmo, mas, bah, é um pre- } \\
\text { conceito sabe, é uma coisa que incomo- } \\
\text { da. (Entrevista 5) }\end{array}$ & $\begin{array}{l}\text { Vítima: estresse, cha- } \\
\text { teação, revolta }\end{array}$ \\
\hline Cor da pele (racial) & Lojas & $\begin{array}{l}\text { Tem um parente direto meu que ele } \\
\text { é negro, ele entrou na minha frente } \\
\text { em uma loja e os seguranças ficaram } \\
\text { cuidando ele, e quando eu entrei na loja } \\
\text { atrás dele, as atendentes vieram per- } \\
\text { guntar o que eu precisava e eu disse que } \\
\text { estava com ele. Então, apesar de eu não } \\
\text { ser negra e ele ser, existe uma diferença. } \\
\text { (Entrevista 14) }\end{array}$ & $\begin{array}{l}\text { Vítima: humilhação, } \\
\text { injustiça }\end{array}$ \\
\hline Corda pele (racial) & Futebol & $\begin{array}{l}\text { O preconceito racial já acabou, mas } \\
\text { isso não é bem verdade. Nós sabemos, } \\
\text { já aconteceram casos, casos recentes, } \\
\text { inclusive no futebol, de preconceitos. } \\
\text { (Entrevista 10) }\end{array}$ & Vítima: revolta \\
\hline $\begin{array}{l}\text { Racial associada à baixa } \\
\text { escolaridade }\end{array}$ & Trabalho & $\begin{array}{l}\text { Teve uma situação em que nós tínha- } \\
\text { mos uma apresentação para fazer para } \\
\text { o presidente da empresa, e na empresa } \\
\text { onde eu trabalho tem uma pessoa que } \\
\text { trabalha lá há muito tempo, ele não } \\
\text { tem escolaridade, mas ele tem bastante } \\
\text { conhecimento, e ele teria condições de } \\
\text { apresentar, o que a gente precisava apre- } \\
\text { sentar para o presidente muito melhor } \\
\text { do que eu. Eu estava recém começando } \\
\text { a trabalhar lá, estava trabalhando lá a } \\
\text { duas, três semanas, e a responsável pelo } \\
\text { setor pediu que eu apresentasse para o } \\
\text { presidente, eu como sendo uma pessoa } \\
\text { já formada, com outra escolaridade, ain- } \\
\text { da que não tivesse por dentro daquele } \\
\text { assunto especificamente, e esse outro } \\
\text { colega tinha muito mais condição de } \\
\text { apresentar do que eu. Acho que foi uma } \\
\text { combinação de escolaridade e racial, } \\
\text { porque ele é negro. (Entrevista 4) }\end{array}$ & $\begin{array}{l}\text { Vítima: injustiça, } \\
\text { culpa }\end{array}$ \\
\hline
\end{tabular}


Quadro 2 (cont.)

\begin{tabular}{|c|c|c|c|}
\hline $\begin{array}{l}\text { MOTIVO DA } \\
\text { DISCRIMINAÇÃO }\end{array}$ & LOCAL & $\begin{array}{l}\text { EXPERIÊNCIA DISCRIMINATÓRIA } \\
\text { PRESENCIADA }\end{array}$ & SENTIMENTOS \\
\hline Por deficiência & Escola & $\begin{array}{l}\text { Eu tenho uma paciente que ela tem } \\
\text { realmente diagnóstico de retardo } \\
\text { mental e ela está na terceira série, com } \\
\text { treze anos. A mãe foi conversar comigo } \\
\text { porque ela era apedrejada, os dedos } \\
\text { dela eram esmagados nas portas do } \\
\text { banheiro, sabe acontecia, teve uma vez } \\
\text { que ela chegou com um vergão no braço } \\
\text { porque um menino deu uma porretada } \\
\text { no braço dela. As crianças não estão nem } \\
\text { aí, vão lá, discriminam e têm preconceito } \\
\text { e não tão nem aí mesmo. Eu acho quer } \\
\text { esse 'bulling' está ligado à discrimina- } \\
\text { ção. Eu acho que as pessoas começam a } \\
\text { ficarem mais conscientes do que é isso, } \\
\text { a discriminação que o outro pode estar } \\
\text { sofrendo, quando ficam mais velhas. } \\
\text { (Entrevista 3) }\end{array}$ & Vítima: inibição \\
\hline Sexual & Estágio & $\begin{array}{l}\text { [...] eu tenho um amigo que é homos- } \\
\text { sexual, e eu acho que influiu muito } \\
\text { quando ele foi procurar estágio, por } \\
\text { exemplo, acho que isso influiu muito } \\
\text { para ele conseguir, tanto que ele era um } \\
\text { guri super inteligente, super esforçado, } \\
\text { tudo, simpático, [...] eu vi que ele não } \\
\text { conseguia estágio, eu acho que pelo } \\
\text { comportamento dele de ser homossexu- } \\
\text { al. (Entrevista 6) }\end{array}$ & $\begin{array}{l}\text { Vítima: tristeza, } \\
\text { pressão }\end{array}$ \\
\hline Sexual & Universidade & $\begin{array}{l}\text { A gente tem um colega gay na nossa } \\
\text { turma e ele sofre discriminação, para } \\
\text { mim é nítida assim, porque os guris da } \\
\text { turma não andam muito com ele, acham } \\
\text { que tem medo de serem tachados, só } \\
\text { porque tão andando com ele, né, então } \\
\text { ele acaba se enturmando mais com as } \\
\text { gurias, e ele mesmo diz que não se sente } \\
\text { à vontade com o restante da turma por } \\
\text { causa disso, porque ele sente que tratam } \\
\text { ele diferente. Eles fazem piadinhas ou sei } \\
\text { lá, se ele tá entrando na sala rola aquele } \\
\text { risinho, aquela coisinha assim, não é } \\
\text { nada muito explicito, né, mas a gente } \\
\text { nota. (Entrevista 7) }\end{array}$ & $\begin{array}{l}\text { Vítima: tristeza, ner- } \\
\text { vosismo }\end{array}$ \\
\hline
\end{tabular}


Quadro 2 (cont.)

\begin{tabular}{|c|c|c|c|}
\hline $\begin{array}{l}\text { MOTIVO DA } \\
\text { DISCRIMINAÇÃO }\end{array}$ & LOCAL & $\begin{array}{l}\text { EXPERIÊNCIA DISCRIMINATÓRIA } \\
\text { PRESENCIADA }\end{array}$ & SENTIMENTOS \\
\hline Sexual & $\begin{array}{l}\text { Todos os } \\
\text { espaços }\end{array}$ & $\begin{array}{l}\text { Já presenciei. Foi algo que eu não } \\
\text { gostaria de ter visto, as pessoas não } \\
\text { têm direito de discriminar ninguém na } \\
\text { sociedade, acho que sempre se deve ter } \\
\text { respeito pelas pessoas. [...] Sim, até em } \\
\text { casa. É algo que é bem amplo que não } \\
\text { tem lugar, que não é delimitado, que não } \\
\text { vai acontecer só no teu trabalho ou na } \\
\text { rua. Tem um espaço bem abrangente. } \\
\text { (Entrevista 13) }\end{array}$ & $\begin{array}{l}\text { Pessoa que presenciou: } \\
\text { constrangimento. } \\
\text { Vítima: injustiça, ver- } \\
\text { gonha, fica retraída, } \\
\text { humilhada, revoltada }\end{array}$ \\
\hline $\begin{array}{l}\text { Por ser inteligente, não } \\
\text { usar roupas de marca e } \\
\text { não jogar futebol com os } \\
\text { amigos }\end{array}$ & Escola & $\begin{array}{l}\text { Tinha um colega, que era o maior exem- } \\
\text { plo que eu vi, ele era muito inteligente, } \\
\text { ele era o cara que era mais excluído da } \\
\text { turma, e por ele nunca revidar, para } \\
\text { mim, foi o cara que mais sofreu. Todo } \\
\text { mundo pegava no pé dele e acho que } \\
\text { como ele não revidava, ficavam pegando } \\
\text { no pé dele cada vez mais, e uma vez teve } \\
\text { até uma briga com ele, que empurraram } \\
\text { ele contra um poste, bateu a cabeça e } \\
\text { sangrou, e foi isso...por ele ser inteli- } \\
\text { gente, e por ele não andar com roupas } \\
\text { de marca, e ele não jogava bola com a } \\
\text { gente, como a turma inteira jogava bola, } \\
\text { talvez... eles chamavam ele de 'bichinha', } \\
\text { quem jogava mal era 'bichinha'... até eu, } \\
\text { às vezes, ficava chamando, mas eu ten- } \\
\text { tava, não querendo me defender, mas eu } \\
\text { tentava fazer amizade porque eu gostava } \\
\text { de estudar também, então talvez por } \\
\text { isso que eu consegui me juntar tanto } \\
\text { com um grupo quanto com o outro. } \\
\text { (Entrevista 8) }\end{array}$ & $\begin{array}{l}\text { Pessoa que presen- } \\
\text { ciou: injustiça }\end{array}$ \\
\hline Idade & Ônibus & $\begin{array}{l}\text { Discriminação de idoso, no ônibus, se ti- } \\
\text { nha alguém sentado no ônibus, naquele } \\
\text { lugar que é reservado a idosos... ocorria } \\
\text { discussões. (Entrevista 9) }\end{array}$ & $\begin{array}{l}\text { Pessoa que presen- } \\
\text { ciou: raiva, injustiça, } \\
\text { nervosismo e verme- } \\
\text { Ihidão }\end{array}$ \\
\hline Orientação sexual & Festas & $\begin{array}{l}\text { Às vezes meus colegas, tipo, eles gostam } \\
\text { dele, mas eles fazem umas piadinhas... } \\
\text { eu nunca perguntei para ele se ele se im- } \\
\text { portava, mas eu não acho legal e, não sei } \\
\text { qual é o sentimento dele. Eu não gosto. } \\
\text { Meus amigos gays, às vezes, se beijam } \\
\text { nas festas; então, algumas pessoas ficam } \\
\text { olhando como se fosse muito estranho. } \\
\text { (Entrevista 11) }\end{array}$ & $\begin{array}{l}\text { Pessoa que presen- } \\
\text { ciou: constrangimento }\end{array}$ \\
\hline
\end{tabular}


Quadro 2 (cont.)

\begin{tabular}{|c|c|c|c|}
\hline $\begin{array}{l}\text { MOTIVO DA } \\
\text { DISCRIMINAÇÃO }\end{array}$ & LOCAL & $\begin{array}{l}\text { EXPERIÊNCIA DISCRIMINATÓRIA } \\
\text { PRESENCIADA }\end{array}$ & SENTIMENTOS \\
\hline Aparência Física & Escola & $\begin{array}{l}\text { Minha irmã sofre bastante com discrimi- } \\
\text { nação pela questão de peso quando ela } \\
\text { era mais novinha, agora continua, mas } \\
\text { quando ela era mais nova estava com so- } \\
\text { brepeso e não emagrecia. Com o aumen- } \\
\text { to de peso os colegas dela chamavam ela } \\
\text { de 'rolha de poço', uns negócios assim. } \\
\text { No espaço escolar pelos colegas, porque } \\
\text { eles fazem a ação de chamar ela, talvez } \\
\text { eles nem pensem, 'estou chamando e tal', } \\
\text { mas eles não sabem que aquela palavra } \\
\text { que eles vão dizer para ela vai afetar ela } \\
\text { emocionalmente. (Entrevista 15) }\end{array}$ & $\begin{array}{l}\text { Pessoa que presen- } \\
\text { ciou: afeta a família } \\
\text { toda, dificulta o diálo- } \\
\text { go na família. } \\
\text { Vítima: ansiedade, } \\
\text { raiva, come demais } \\
\text { porque fica tensa, } \\
\text { nervosa e acaba en- } \\
\text { gordando (sofrimento } \\
\text { psicológico) }\end{array}$ \\
\hline
\end{tabular}

Para os estudantes que vivenciaram a discriminação, os motivos citados relacionaramse à aparência física e cor da pele. Por sua vez, nos relatos das experiências presenciadas, estas foram percebidas, especialmente, em relação à cor da pele e por questões ligadas à sexualidade. Todas as experiências referiram-se a atos de discriminação cometidos por um indivíduo diretamente a outro - discriminação interpessoal ${ }^{33}$. Tais experiências não tiveram um motivo único para a discriminação. Pelo contrário, os múltiplos motivos foram relatados de forma associada, confirmando a complexidade do fenômeno e a possibilidade de serem experienciados simultaneamente por suas vítimas ${ }^{23,32,34}$.

Em relação ao local da experiência discriminatória, a escola foi o domínio mais identificado pelos estudantes. Tais relatos se referiram a fatos ocorridos no passado, quando os universitários ainda estavam no período de formação escolar básica - Ensino Fundamental e Médio. Nas experiências mais recentes, foi observada diversidade de espaços e contextos em que a discriminação se manifestou - universidade, família, rua, ônibus, trânsito, lojas, festas e no trabalho - assim como relatado na literatura ${ }^{8,10,23}$.

Tanto a exposição à discriminação na condição de vítima quanto de testemunha se vinculou a diversos sentimentos negativos nos estudantes. O sentimento mais frequentemente relatado foi o de "tristeza", sendo este associado à frustração, reclusão e impotência, insegurança e vergonha, "humilhação" e "inibição". Outros sentimentos mencionados pelos universitários foram "inibição associada à baixa autoestima”, "inibição associada à vergonha", "vergonha", "injustiça”, "solidariedade e pena”, "desapontamento", "sentir-se chateado associado à revolta", "sentir-se reprimido", "sentir-se ridicularizada", "raiva” e "ódio".

De modo similar, Cecchetto e Monteiro ${ }^{34}$ também identificaram, em jovens do sexo masculino do Rio de Janeiro, sentimentos denominados de interiorização negativa, os quais foram representados por relatos de humilhação, constrangimento, tristeza e mal-estar. Currie et $a_{.}{ }^{10}$, ao entrevistarem estudantes universitários aborígenes do Canadá, descreveram inúmeras reações à discriminação, incluindo choque e frustração, além de sentimentos de desamparo e desesperança, explicando que, muitas vezes, os estudantes sofriam em silêncio, inibindo-se. Estudo sobre discriminação racial em uma comunidade negra nos Estados Unidos $^{35}$ indicou sentimentos de raiva, ansiedade, tristeza e desapontamento associados à discriminação. Soto et al. ${ }^{36}$ verificaram, em universitários latinos de 19 universidades dos Estados Unidos, sentimentos de raiva, ansiedade e tristeza como as respostas mais comuns à discriminação percebida e argumentaram que a regulação das emoções negativas é altamente necessária para a pessoa lidar com o evento. 
Outro sentimento que merece destaque nos relatos dos estudantes foi o de solidariedade às vítimas da discriminação. O ato discriminatório é um problema social ${ }^{37}$ e, não raro, entre as pessoas que a testemunham, pode ocorrer uma forte identificação do sentimento de solidariedade ${ }^{38}$, como observado neste estudo.

Há de se levar em consideração que como o preconceito é moralmente condenado e a discriminação está juridicamente sujeita à punição, suas manifestações explícitas tornam-se cada vez mais sutis ${ }^{32}$. As falas dos universitários entrevistados sugeriram a importância social do 'não discriminar' ou 'não ter preconceito' contra determinado grupo e de referirem-se à discriminação como uma atitude negativa. Apesar disso, os estudantes também manifestaram a presença do preconceito e de atitudes discriminatórias em sua trajetória de vida.

[...] na nossa cabeça, querendo ou não, quando tem, por exemplo, um assaltante, não vou dizer generalizado, mas a maioria é negro, tem aquele estereótipo, daí acaba aquelas outras pessoas que têm aquela mesma característica sofrendo preconceito, sem ser. (Estudante 6, sexo feminino, 20 anos)

Tanto para as narrativas das experiências vivenciadas quanto nas presenciadas, os universitários mostraram a discriminação trazendo prejuízos à vida de suas vítimas e despertando sentimentos negativos. Tais experiências foram presenciadas, muitas vezes, no contexto da família dos estudantes (pai, irmã), o que pode explicar a percepção imediata da discriminação e os sentimentos negativos relatados.

Para esses universitários, as implicações de vivenciar ou presenciar eventos discriminatórios foram praticamente as mesmas, trazendo relevância às duas situações e mostrando a importância de se avaliar não só a discriminação que se vivencia, mas também a que se presencia. Também se torna oportuno considerar, em pesquisa futuras, se há diferentes implicações em se presenciar a discriminação sofrida por um familiar próximo ou por um desconhecido.

As limitações deste estudo dizem respeito à possibilidade de generalização dos resultados, que se restringe aos estudantes universitários entrevistados, com uma faixa etária limitada, a maioria brancos e de alto nível de escolaridade. Esses entrevistados não representam, portanto, as experiências discriminatórias vivenciadas e/ou presenciadas por outros grupos populacionais. Ainda, o estudo destaca a subjetividade da experiência de discriminação.

\section{CONCLUSÃo}

Seja do ponto de vista de vítima ou de testemunha, as experiências discriminatórias atravessaram o cotidiano dos entrevistados em seus variados domínios e circunstâncias. Os universitários investigados reconheceram o fenômeno da discriminação e das experiências discriminatórias como atos injustos e prejudiciais à vida de suas vítimas, despertando sentimentos negativos, tanto nas experiências vivenciadas quanto nas presenciadas. Nas experiências discriminatórias presenciadas, as que envolveram pessoas próximas dos estudantes, de seu núcleo familiar, foram percebidas como as que mais os afetaram negativamente. Houve a identificação dos estudantes não somente como vítimas da discriminação, mas também, como perpetradores. O sentimento de solidariedade às vítimas da discriminação foi evidenciado pelo grupo. A universidade foi identificada como um espaço preferencial para manifestação da discriminação, especialmente por motivo sexual e pelo turno de realização do curso. A discriminação foi associada, nesse grupo de universitários, a um comportamento 
observável, com caráter negativo. Reiterou-se a ideia de que os motivos pelos quais os participantes percebem que foram discriminados podem ser múltiplos e, ainda, estar associados, além do reconhecimento de que vítimas também se reconheceram como perpetradores de discriminação.

A opção metodológica deste estudo pela técnica da entrevista individual trouxe a possibilidade de uma maior interação entre pesquisadores e participantes da pesquisa, o que favoreceu a compreensão de cada contexto e subjetividades envolvidos nas experiências discriminatórias vivenciadas e/ou presenciadas, tornando possível analisar o modo com que tais experiências afetaram/marcaram a vida desses estudantes. A utilização de metodologias qualitativas de pesquisa deve ser estimulada como parte da validação teórica de construtos abstratos, contexto-dependentes, que pretendem ser mensurados de forma quantitativa em inquéritos populacionais. Entende-se que este estudo exploratório de natureza qualitativa tem potencial para contribuir com o aperfeiçoamento de escalas de discriminação, trazendo aspectos que devem ser considerados quando da construção/validação dessas escalas.

\section{REFERÊNCIAS}

1. Taguieff PA. O racismo. Lisboa: Instituto Piaget; 1997.

2. Krieger N. A glossary for social epidemiology. ] Epidemiol Community Heal. 2001; 55(10):693-700.

3. Godoi AAMM, Garrafa V. Leitura bioética do princípio de não discriminação e não estigmatização. Saude e Sociedade. 2014; 23 (1):110-18

4. Celeste RK, Bastos ]L, Faerstein E. Trends in the investigation of social determinants of health: selected themes and methods. Cad Saude Publica. 2011; 27(1):183-9.

5. Bastos ]L, Faerstein E, Celeste RK, Barros AJD. Explicit discrimination and health: development and psychometric properties of an assessment instrument. Rev Saude Publica. 2012; 46(2):269-78.

6. Garcia A, Souza EM. Sexualidade e trabalho: estudo sobre a discriminação de homossexuais masculinos no setor bancário. RAP. 2010; 44(6):1353-77.

7. Bittencourt AA, Aerts DRCC, Alves GG, Palazzo L, Monteiro L, Vieira PC, et al. Sentimento de discriminação em estudantes: prevalência e fatores associados. Rev Saude Publica. 2009; 43(2):236-45.

8. Silva GM, Reis EP. Perceptions of racial discrimination among black professionals in Rio de Janeiro. Lat Am Res Rev. 2011; 46(2):55-78.

9. Conzales KL, Lambert WE, Rongwei F, Jacob M, Harding AK. Perceived racial discrimination in health care, completion of standard diabetes services, and diabetes control among a sample of American Indian women. Diabetes Educ. 2014; 40(6):747-55.

10. Currie CL, Wild C, Schopflocher DP, Laing L, Veugelers P. Racial discrimination experienced by Canadian Aboriginal university students. Can ] Psychiatry. 2012; 57(10):617-25.

11. Gökçe AT. University students' perception of discrimination on campus in Turkey. Journal of Higher Education Policy and Management. 2013; 35(1):72-84

12. Pocahy F. Um mundo de injúrias e outras violações. Reflexões sobre a violência heterossexual e homofóbica a partir da experiência do CRDH rompa o silêncio. In: Pocahy F. Rompendo o silêncio: homofobia e heterossexismo na sociedade contemporânea. Políticas, teoria e atuação. Porto Alegre: Nuances; 2007.

13. Parker R. Stigma, prejudice and discrimination in global public health. Cad Saude Pública. 2012; 28(1):164-9.

14. Bastos ]L, Barros AJD, Celeste RK, Paradies YC, Faerstein E. Age, class and race discrimination: their interactions and associations with mental health among Brazilian university students. Cad saúde pública. 2014; 30(1):175-86.

15. Pascoe EA, Richman LS. Perceived discrimination and health: a meta-analytic review. Psychol Bull. 2009; 135(4):531-54.

16. Couto PF, Goto JB, Bastos ]L. Pressão arterial e discriminação interpessoal: revisão sistemática de estudos epidemiológicos. Arq Bras Cardiol. 2012; 99(4):956-63.

17. Williams DR, Mohammed SA. Discrimination and racial disparities in health: evidence and needed research.] Behav Med. 2009; 32(1):20-47.

18. Souza MVC, Lemkuh II I, Bastos ]L. Discriminação e sofrimento psíquico de graduandos da Universidade Federal de Santa Catarina. Rev bras epidemiol. 2015; 18(3): 525-37. 
19. Coelho IZ, Bastos ]L, Celeste RK. Moderators of the association between discrimination and alcohol consumption: findings from a representative sample of Brazilian university students. Trends Psychiatry Psychother. 2015; 37(2):72-81.

20. Brown CS. The Educational, psychological, and social impact of discrimination on the immigrant child. Washington, DC: Migration Policy Institute; 2015.

21. Ávila RC. Formação das mulheres nas escolas de Medicina. Revista Brasileira de Educação Médica. $2014 ; 38$ (1): 142-9.

22. Bastos ]L, Faerstein E. Discriminação e saúde: perspectivas e métodos. Rio de Janeiro: Fiocruz; 2012.

23. Bastos ]L, Gonçalves H, Faerstein E, Barros AJD. Experiências de discriminação entre universitários do Rio de Janeiro. Rev Saude Publica. 2010; 44(1): 28-38.

24. Brasil. Lei n¹2711, de 29 de agosto de 2012. Acesso em: http://www.planalto.gov.br/ccivil_03/_ato2011-2014/2012/ lei/l12711.htm .

25. Flick U. Introdução à pesquisa qualitativa. 3. ed. Porto Alegre: Artmed; 2009

26. Rosa MVFPC, Arnoldi MACC. A entrevista na pesquisa qualitativa: mecanismo para validação de resultados. Belo Horizonte: Autêntica; 2008.

27. Bardin L. Análise de conteúdo. São Paulo: Edições 70; 2011.

28. Matthews E. Compreender Merleau-Ponty. 2. ed. Petrópolis: Vozes, 2011.

29. Correll J, Judd CM, Park B, Wittenbrink B. Measuring prejudice, stereotypes and discrimination. In: Dovidio JF, Hewstone M, Glick P, Esses VM (ed.). The Sage handbook of prejudice, stereotyping and discrimination. London: SACE; 2010. p. 45-62.

30. Oliveira CLP, Barreto PCS. Percepção do racismo no Rio de Janeiro. Estudos Afro-Asiáticos. 2003; 25(2):183-213.

31. Dovidio JF, Hewstone M, Glick P, Esses V. Prejudice, stereotyping, and discrimination: theoretical and empirical overview. In: Dovidio JF. The sage handbook of prejudice, stereotyping, and discrimination. London: Sage; 2010.

32. Bandeira L, Batista AS. Preconceito e discriminação como expressões de violência. Estudos Feministas. 2002; 10(1):119-41.

33. Plous S. Understanding prejudice and discrimination. New York: McGraw-Hill; 2003.

34. Cecchetto F, Monteiro S. Discriminação, cor e intervenção social entre jovens na cidade do Rio de Janeiro (R], Brasil): a perspectiva masculina. Estudos Feministas. 2006; 14(1):199-218.

35. Shultz C, Skorcz S. African American infant mortality and the Genesee County, MI REACH 2010 initiative: an evaluation of the Undoing Racism Workshop. Soc Work Public Health. 2012; 27(6):567-603.

36. Soto, JA, Armenta BE, Perez CR, Zamboanga BL, Umaña-Taylor AJ, Lee RM, et al. Strength in numbers? Cognitive reappraisal tendencies and psychological functioning among Latinos in the context of oppression. Cultur Divers Ethnic Minor Psychol. 2012; 18(1): 384-94.

37. Lima MEO, Vala ]. As novas formas de expressão do preconceito e do racismo. Estudos de Psicologia. 2004; 9(3):401-11.

38. Campos ID, Stripling AM, Heesacker M. "Estoy viejo" [I'm old]: internalized ageism as self-referential, negative, ageist speech in the Republic of Panama. J Cross Cult Gerontol. 2012; 27(4):373-90. 